\title{
Serum malondialdehyde, coenzyme Q10 and 8-hydroxy-2-deoxyguanosine levels in calves with foot-and-mouth disease
}

\author{
CUMALI ÖZKAN, ZÜBEYIR HUYUT*, SERKAN YILDIRIM**, \\ MUSTAFA ÖZBEK, HASAN ICEN***
}

\begin{abstract}
Department of Internal Medicine, Faculty of Veterinary Medicine, Van Yuzuncu Yil University, Van-Turkey
*Department of Biochemistry, Faculty of Medicine, Van Yuzuncu Yil University, Van-Turkey

${ }^{* *}$ Department of Pathology, Faculty of Veterinary Medicine, Ataturk University, Erzurum-Turkey

***Department of Internal Medicine, Faculty of Veterinary Medicine, Dicle University, Diyarbakir-Turkey
\end{abstract}

\section{Özkan C., Huyut Z., Yildirim S., Özbek M., Icen H. \\ Serum malondialdehyde, coenzyme Q10 and 8-hydroxy-2-deoxyguanosine levels \\ in calves with foot-and-mouth disease}

\section{Summary}

Foot-and-mouth disease (FMD) is an acute, contagious viral disease in cattle that is associated with enormous economic losses in Turkey and worldwide. The purpose of this study was to determine changes in serum malondialdehyde (MDA), coenzyme Q10 (CoQ10), 8-hydroxy-2-deoxyguanosine (8-OHdG) and deoxyguanosine (dG) and to perform histopathological examinations in calves with FMD. Thirty calves were studied, 20 of which were infected with FMD and 10 were free of the disease. Following a routine clinical examination, blood samples were obtained, and serum MDA, CoQ10, 8-OHdG and dG levels were determined. Necropsy and histopathological examinations were performed on dead calves with FMD. MDA and 8-OHdG/10 6 dG levels were significantly higher in calves with FMD than in the control group. However, the increase in CoQ10 levels in calves with FMD, compared with the control group, was not statistically significant. Macroscopic examination of the heart tissue of calves with acute myocarditis revealed the presence of pale, yellowish gray-white necrotic muscle fibers in the ventricular wall of the heart. The muscle fibers in the myocardium were swollen and exhibited pyknotic nuclei and intense lymphocytic cell infiltration. In longitudinal sections, the muscle fibers were non-striated, swollen, and homogenously pink and contained pink nuclei. Between muscle fibers, intense mononuclear cell infiltration was observed. The findings of the present study indicate that oxidative stress is significantly increased in calves with FMD, and that oxidative DNA damage may play an important role in the etiopathogenesis of FMD. This is the first study to report CoQ10 and 8-OHdG levels in calves with FMD, and its findings may serve as the basis for future studies on this subject.

Keywords: foot-and-mouth disease, myocarditis, MDA, CoQ10, 8-OHdG

Foot-and-mouth disease (FMD) is an acute, contagious viral disease that affects domestic and wild cloven-hoofed animals and leads to enormous economic losses $(23,27)$. It is caused by aphthovirus, an RNA virus (FMDV) from the family Picornaviridae (1). There are seven serotypes of FMDV, namely O, A, C, SAT 1-3 and Asia 1, and about 60 subtypes. FMD occurs enzootically in Africa, Asia (including Turkey) and occasionally in South America $(1,6,8,12,27)$.

FMD is common in domestic animals, such as cattle, sheep, goats and swine, but the disease progresses more severe in cattle than it does in sheep or goats $(1,8,23)$.
The clinical signs of this disease in cattle are increased body temperature, loss of appetite, difficulty in eating, vesicle formation in the mouth, on the tongue, gums, palate, udder and coronary band, as well as lameness, and the drooling of stringy saliva. The clinical course worsens as a result of secondary infections. The virus has an affinity for the cardiac muscle, and macroscopic observation reveals a tiger fur-like appearance of the heart in animals with affected cardiac muscles $(1,8$, 14). This affinity for the cardiac muscle makes FMD particularly devastating in young animals, which eventually die as a result of muscle damage and myocarditis 
$(14,27)$. Therefore, while the mortality rate is $5 \%$ in adult animals, it may reach up to $50 \%$ in young animals $(1,8,14,23)$.

In order to obtain detailed information about diseases in animals, it is important to measure biochemical parameters and compare them between infected animals and healthy animals (10). Changes in various biochemical parameters, especially those related to cardiac function, have been reported in animals with FMD, especially young ones. However, it is important to explore other biochemical markers in order to improve the diagnosis and treatment of this disease $(6,12,23)$.

Occasionally, the balance between oxidants and antioxidants may be altered in certain conditions, and as a result, oxidative stress may occur. In normal conditions, free radicals are produced during cellular metabolism. When antioxidants are absent or few, these free radicals may have an effect on lipids, carbohydrates, proteins and nucleic acid, and thereby lead to oxidative stress $(3,19,21)$. Oxidative damage caused by oxidative stress is believed to play a role in the pathogenesis of several diseases, including cardiovascular disorders $(19,21)$. There are several biochemical markers of oxidative stress, including malondialdehyde (MDA). MDA is the final product of lipid peroxidation, and it is therefore commonly used as an indicator of lipid peroxidation. In addition, it has adverse effects on ion transport, enzymatic activities and cell membranes, and it is used as an indicator of the severity of cellular damage $(3,7)$.

Another marker of oxidative stress is ubiquinone 10 (CoQ10), which is a lipid structured compound of the mammalian mitochondrial electron chain that prevents damage caused by biomolecules and lipid peroxidation by playing a role in the production of active forms of ascorbic acid and tocopherol $(9,16)$. CoQ10 is important for cardiac muscle function, and it plays a role as an antioxidant in cardiac disorders and heart failures. CoQ10 is a strong antioxidant that protects cellular structure by eliminating free radicals $(9,16,18)$.

8-hydroxy-2-deoxyguanosine (8-OHdG) is the most abundant marker of oxidative DNA damage. Reactive oxygen species (ROS) are produced when antioxidants are absent or scarce. These ROS may damage lipids, proteins and particularly DNA $(4,5,20,22)$. When DNA suffers oxidative damage as a result of ROS, $8-\mathrm{OHdG}$ is produced as one of the products of the damage. $8-\mathrm{OHdG}$ is one of the best characterized DNA markers associated with cellular damage. $8-\mathrm{OHdG}$ is an indicator of aging, carcinogenesis and oxidative stress in animals and humans that can be measured in samples, such as urine, tissue, leucocyte DNA and even serum $(3,19,21,26)$. While numerous studies have evaluated these parameters of oxidative stress in human diseases $(5,9,16,24)$, there are no studies on serum MDA, CoQ10 and 8-OHdG levels in calves with FMD. In addition, in most biochemical studies on
FMD in calves, mainly parameters related to cardiac markers such as troponin, troponin $\mathrm{T}$, troponin I etc. were examined $(6,12,23)$.

The purpose of the study was to assess changes in serum MDA, CoQ10, 8-OHdG and deoxyguanosine (dG) levels and to examine the histopathological features of calves with FMD.

\section{Material and methods}

The study included 30 calves, 20 of which had FMD and 10 were healthy. The calves were of different breeds (Holstein and Simmental), ages (1-6 months) and sexes. The animals were brought to our clinics from the cities of Van and Erzurum. Blood samples from the jugular vein were collected into tubes containing EDTA and tubes without EDTA. Blood samples in anticoagulant-free tubes were centrifuged (Rotofix $32^{\circledR}$-Hettich) for $10 \mathrm{~min}$ at $3000 \mathrm{rpm}$, and serum samples were extracted. MDA, CoQ10, 8-OHdG and $\mathrm{dG}$ levels were measured at Van Yuzuncu Yil University, Faculty of Medicine, Department of Biochemistry, with a high-pressure liquid chromatography (HLPC) device (Agilent 1200 modular system, Boblingen, Germany).

To obtain definite diagnosis and to identify serotypes, the blood samples were delivered to the Ankara Foot-andMouth Disease Institute via the Provincial Directorate of Food, Agriculture and Livestock. According to the results of the Foot-and-Mouth Disease Institute, there were four ASIA 1 and sixteen A serotypes in the samples. Blood samples positive for FMD were used in this study.

Calves that died despite treatment were delivered to the pathology laboratory for pathological and histopathological examinations and systemic necropsy. Pathological findings were recorded, and in order to perform histological examinations, heart tissues with lesions were fixed in a $10 \%$ formalin solution for $48 \mathrm{~h}$ and washed under flowing tap water for $10 \mathrm{~h}$. For the histological examination, tissues were embedded in paraffin blocks after they had been passed through an alcohol and xylol series. Sections of $4 \mu \mathrm{m}$ thickness were obtained from every block, and the tissues were prepared on microscope slides. The prepared tissues were stained with hematoxylin-eosin (H\&E) and examined under a light microscope (Leica DM 1000, Germany).

MDA analysis. The MDA concentration in the serum samples was measured with an HPLC device (Agilent 1200 mobile system; Boblingen, Germany) by a previously described method (13). For HPLC, $750 \mu \mathrm{L} \mathrm{H}_{3} \mathrm{PO}_{4}(0.44$ $\mathrm{mol} / \mathrm{L}$ ) and $250 \mu \mathrm{L}$ thiobarbutiric acid (TBA, $42 \mathrm{mmol} / \mathrm{L}$ ) were added to $50 \mu \mathrm{L}$ of the serum sample, and the solution was placed in a boiling water bath for $30 \mathrm{~min}$. After cooling in icy water, alkaline methanol (methanol containing $4.5 \mathrm{~mL}$ of $1 \mathrm{M} \mathrm{NaOH}$ : total volume $54,5 \mathrm{~mL}$ ) was added in equal volume to the samples. After strong vortexing, the samples were centrifuged at $3000 \mathrm{rpm}$ for $3 \mathrm{~min}$. The upper phase that formed was transferred to vials and placed in an HPLC device (HP, Agilent 1200 modulary system; Bonlingen, Germany). RP-C18 (particle size: $5 \mu \mathrm{m}$, length: $150 \mathrm{~mm}$, diameter: $4.6 \mathrm{~mm}$ ) columns were used. The mobile phase was an absolute methanol $/ 50 \mathrm{mM} \mathrm{KH_{2 }} \mathrm{PO}_{4}$ buffer of $\mathrm{pH}$ $6.8(40: 60, \mathrm{v} / \mathrm{v})$. The flow rate and injection volume were adjusted to $0.8 \mu \mathrm{L}$ and $20 \mu \mathrm{L}$, respectively. MDA measure- 
ment was performed with a fluorescent detector at an excitation wavelength of $527 \mathrm{~nm}$ and an emission wavelength of $551 \mathrm{~nm}$. The spike of the MDA-TBA complex was calibrated with a 1,1,3,3-tetraethoxypropane standard solution. MDA concentrations were expressed in $\mu \mathrm{M}$.

CoQ10 analysis. The analysis of oxidated CoQ10 was performed according to the method used by Litarru et al. (15). This method involves a direct injection of 1-propanol into the HPLC device and forcing reduced CoQ10 to oxidize that exists in para-benzoquinon applied samples. For HPLC analysis, a reverse-phase ODS supercoil C-18 (particle size: $3 \mu \mathrm{m}$, length: $15 \mathrm{~cm}$, inner diameter: $0.46 \mathrm{~cm}$ ) was used as the column. Serum samples $(200 \mu \mathrm{L})$ were mixed with $50 \mu \mathrm{L} 1$,4-benzoquinon $(2 \mathrm{mg} / \mathrm{mL})$ by vortexing. The solution was incubated at room temperature for $10 \mathrm{~min}$, after which $1 \mathrm{~mL}$ n-propanol was added, and it was vortexed for $10 \mathrm{~s}$. The mixture was centrifuged for $2 \mathrm{~min}$ at $600 \mathrm{rpm}$. Then, $200 \mu \mathrm{L}$ of the supernatant was collected, transferred into a vial and loaded onto the HPLC device. For spectral analysis, the UV detector was adjusted to $275 \mathrm{~nm}$, and the flow rate of the ethanol/methanol $(65: 35, \mathrm{v} / \mathrm{v})$ mobile phase was adjusted to $1 \mathrm{~mL} / \mathrm{min}$. When the column was stabilized, oxidized CoQ10 was measured with the UV detector. The findings are shown in $\mu \mathrm{M}$.

8-OHdG and dG measurement. In order to extract DNA from leukocytes separated from whole blood, a DNA isolation kit (GenAll DNA extraction kit; GenAll Biotechnology Co.Ltd., Seoul, Korea) including the spin column method was used according to the manufacturer's instructions The isolated DNA samples were hydrolyzed with formic acid at $150^{\circ} \mathrm{C}$ for $8-\mathrm{OHdG}$ analysis according to a previously described method (11). The hydrolyzed DNA samples were dissolved in acetonitrile (final volume, $1 \mathrm{~mL}$ ), and 8-OHdG and $\mathrm{dG}$ levels were measured with ECD and UV detectors, respectively, in an HPLC device. A reverse-phase C-18 (RP-C18) analytical column (particle size: $4.0 \mu \mathrm{m}$, diameter: $250 \mathrm{~mm}$, length: $4.6 \mathrm{~mm}$; Phenomenex, CA) was used for HPLC. The mobile phase was a $0.05 \mathrm{M}$ potassium phosphate buffer (pH 5.5) and absolute acetonitrile mixture (97:3, $\mathrm{v} / \mathrm{v}$ ). The flow rate was adjusted to $1 \mathrm{~mL} / \mathrm{min}$, and injection volume was adjusted to $20 \mu \mathrm{L}$. In the HPLC device, the amount of 8-OHdG was determined by adjusting the ECD detector to $600 \mathrm{mV}$, and dG was measured at an absorbance wavelength of $245 \mathrm{~nm}$. The $8-\mathrm{OHdG}$ and $\mathrm{dG}$ standards used for $8-\mathrm{OHdG}$ and $\mathrm{dG}$ measurement were provided by Sigma Aldrich. The $8-\mathrm{OHdG}$ values were expressed as $8-\mathrm{OHdG} / 10^{6} \mathrm{dG}$ for each $10^{6} \mathrm{dG}(22)$.

Histopathological examinations. Systemic necropsy was performed on dead calves. For histopathological evaluation after necropsy, heart muscle tissues obtained from the bodies were fixed in a $10 \%$ formalin solution for $48 \mathrm{~h}$ and washed under tap water for $10 \mathrm{~h}$. For routine tissue tracking, the samples were passed through an alcohol and xylol series prior to embedding in paraffin blocks. Sections of $4 \mu \mathrm{m}$ thickness were obtained from every block and prepared on microscope slides. The preparations were stained with H\&E and examined under a light microscope.

Statistical analyses. For continuous variables, definitive statistical values were expressed as mean and standard deviation. Following variant analysis, Student's t test was used for comparisons between groups. Statistical significance was accepted at 5\% $(\mathrm{p}<0.05)$, and the SPSS 20 software (SPSS Inc., IL, USA) was used for calculations.

\section{Results and discussion}

Clinical symptoms. According to the anamnesis of the animal owners, the clinical signs in the adult animals were similar to those for FMD. However, some of the calves that were found dead had not exhibited any clinical signs. A routine clinical examination was performed on calves brought to our clinics. Physical examination revealed increased body temperature and the presence of vesicles in the mouth, on the tongue and gums. Further, erosions and ulcer formation were observed in these regions after rupture of the vesicles, as well as lameness in some animals. In some calves, none of the classic symptoms of FMD were found. Increased body temperature, heart rate and respiratory rate were noted in all animals.

Values of biochemical parameters. The oxidative stress parameters assessed are shown in Tab. 1 and Fig. 1. The levels of $8-\mathrm{OHdG} / 10^{6} \mathrm{dG}$ and MDA were significantly higher in calves with FMD than in the control groups (MDA: $2.541 \pm 0.219 \mu \mathrm{M}$ vs. 1.962 $\pm 0.126 \mu \mathrm{M}, 8-\mathrm{OHdG} / 10^{6} \mathrm{dG}: 1.481 \pm 0.156$ vs. 1.028 $\pm 0.146 ; \mathrm{p}<0.05$ for both). Oxidized CoQ10 levels were higher in the calves with FMD, but the difference in comparison with the control group was not statisti-

Tab. 1. Values of selected oxidative stress parameters in control group and in calves with foot-and-mouth disease

\begin{tabular}{|l|c|c|}
\hline \multicolumn{1}{|c|}{ Parameter } & $\begin{array}{c}\text { Control Group } \\
\mathrm{n}=10\end{array}$ & $\begin{array}{c}\text { Calves with FMD } \\
\mathrm{n}=20\end{array}$ \\
\hline $\mathrm{MDA}(\mu \mathrm{M})$ & $1.962 \pm 0.126$ & $2.541 \pm 0.219^{*}$ \\
$\mathrm{CoQ} 10(\mu \mathrm{M})$ & $1.495 \pm 0.144$ & $1.719 \pm 0.251$ \\
\hline $8-0 \mathrm{HdG} / 10^{6} \mathrm{dG}$ ratio & $1.028 \pm 0.146$ & $1.481 \pm 0.156^{*}$ \\
\hline
\end{tabular}

Explanation: * - significant compared to control group calves

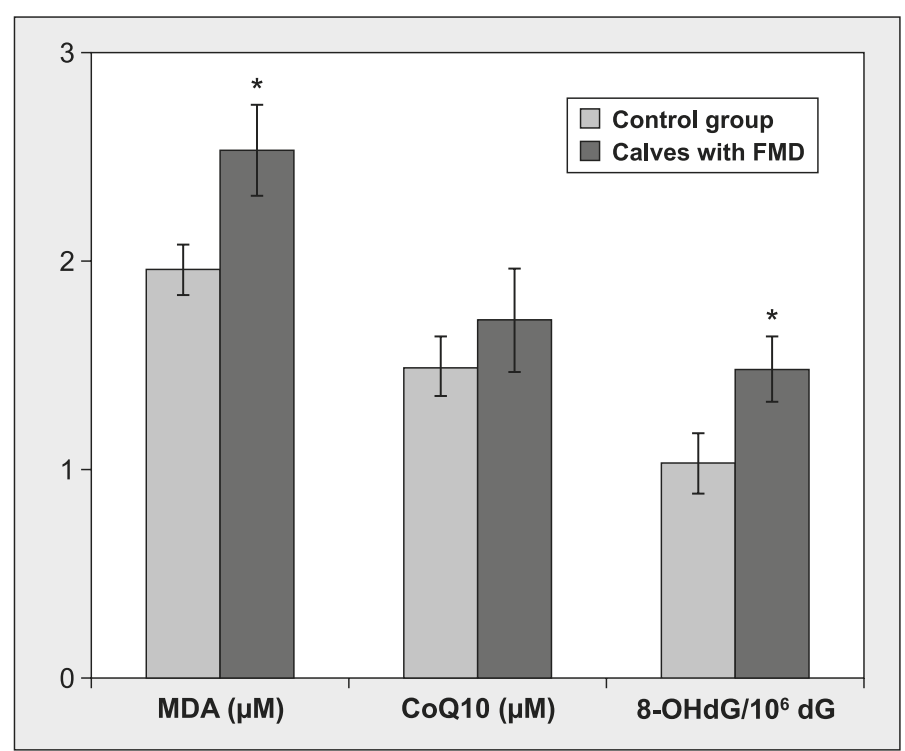

Fig. 1. Comparison of oxidative stress parameters in control group and in calves with foot-and-mouth disease 


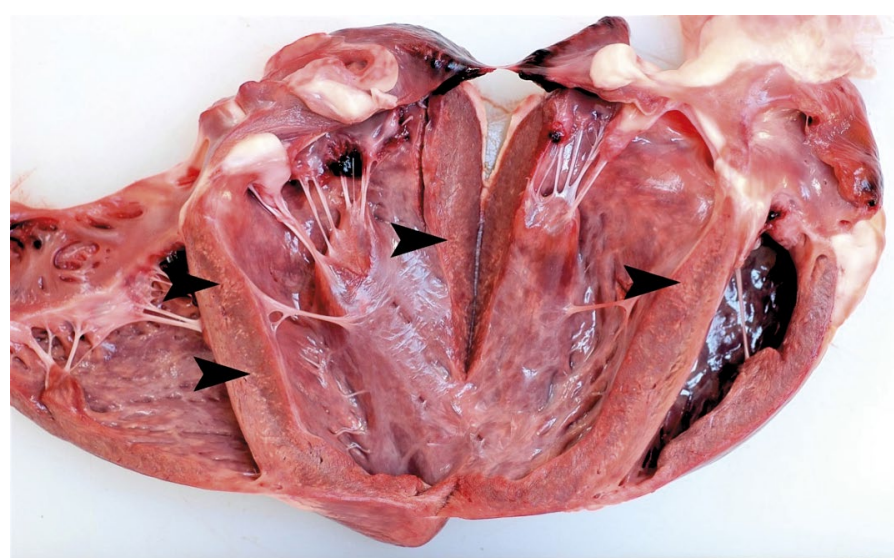

Fig. 2. Acute necrotic myocarditis in heart muscle (arrow heads)

cally significant $(1.719 \pm 0.251 \mu \mathrm{M}$ vs. $1.495 \pm 0.144$ $\mu \mathrm{M}, \mathrm{p}>0.05)$.

Macroscopic and microscopic changes. Calves with acute myocarditis exhibited pale, yellowish graywhite necrotic muscle fibers in the ventricle wall of the heart (Fig. 2). In calves that died of acute myocarditis, coagulated blood was observed in the ventricle lumen, as well as pulmonary edema and a small amount of exudate in the pericardium and in the thoracic and abdominal cavities.

In cardiac tissue, myocardial muscle fibers were swollen, and the nuclei were pyknotic; further, intense lymphocytic cell infiltration was observed in this region (Fig. 3). In longitudinal sections, muscle fibers were non-striated, swollen and homogenously pink and had pyknotic nuclei. Further, intense mononuclear cell infiltration was observed between muscle fibers (Fig. 4). This cellular infiltration was so intense in certain regions that muscle fibers there could not be clearly observed (Fig. 5).

The clinical examinations conducted in this study showed an increase in body temperature, presence of vesicles in the mouth, on the tongue and gums, as well as erosions and ulcerations in places where the vesicles had ruptured. Lameness was also observed in some calves. These clinical findings are similar to those reported in previous studies on $\operatorname{FMD}(1,8,14)$. Some of the calves included in the present study died suddenly before exhibiting any clinical symptoms. We believe that the reason for the sudden death was acute myocarditis. This is corroborated by other studies (14, 27 ), which report that in young animals this disease may lead to death caused by myocarditis, since the virus has affinity for cardiac muscle.

In this study, coagulated blood was observed in the ventricle lumen of the heart, as well as pulmonary edema and a small amount of exudate in the pericardium and in the thoracic and abdominal cavities. In addition, pale, yellowish gray-white necrotic muscle fibers were observed in the ventricle wall muscle. Microscopic observation of the cardiac tissue revealed that the muscle fibers in the myocardium were swollen

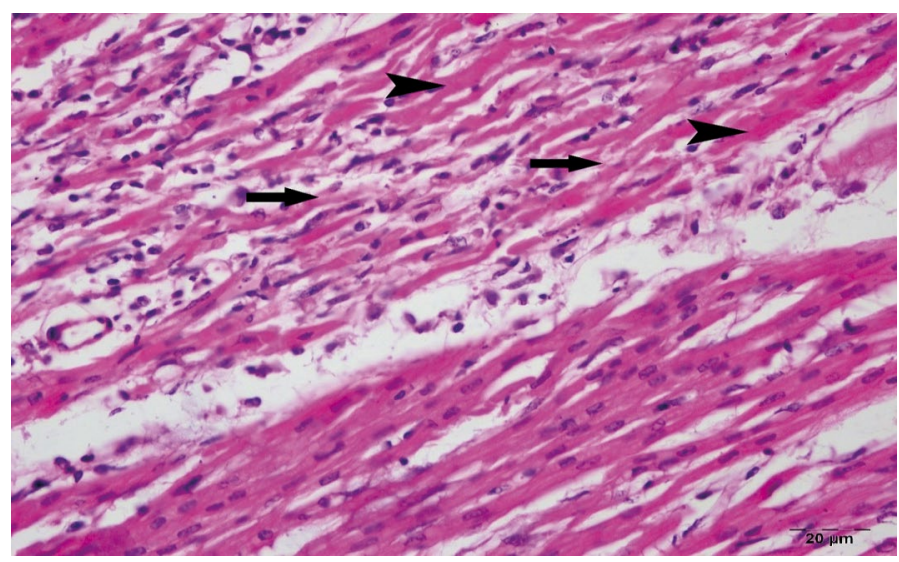

Fig. 4. Longitudinal section of cardiac muscle: hyalin degeneration in muscle fibers (arrows), Zenker necrosis (arrow head), mononuclear cell infiltration between muscle fibers, H\&E Bar: $20 \mu \mathrm{m}$

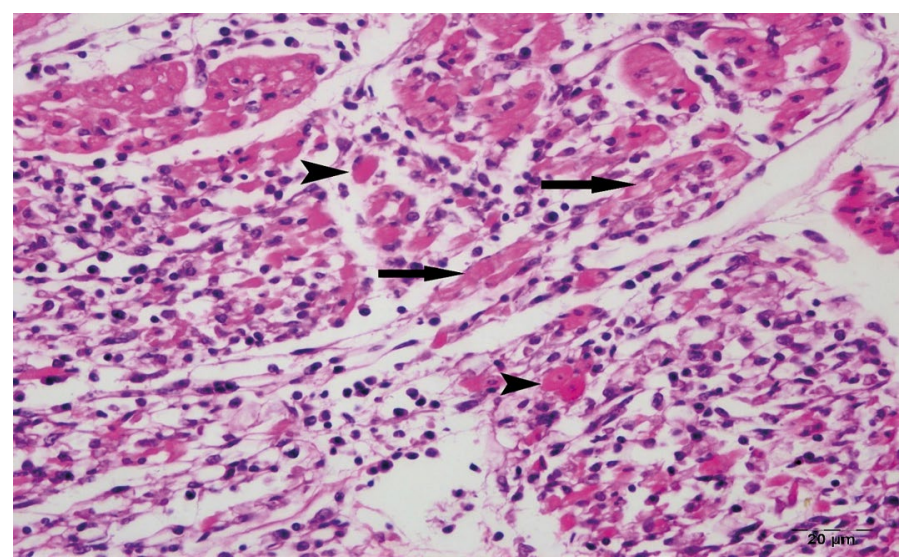

Fig. 3. Transverse section of cardiac muscle: hyalin degeneration in muscle fibers (region shown with arrows), Zenker necrosis (arrow head), intense mononuclear cell infiltration, H\&E Bar: $50 \mu \mathrm{m}$

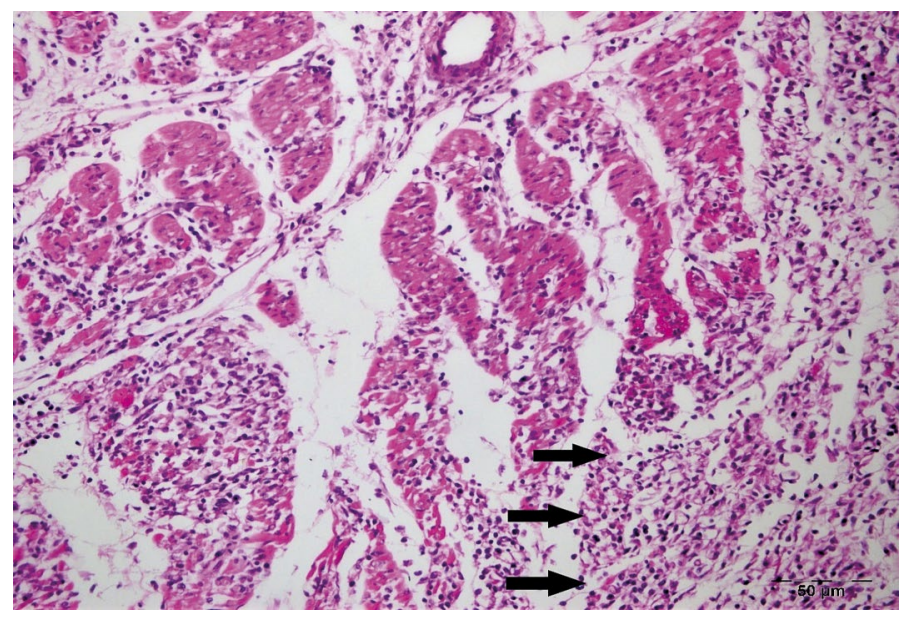

Fig. 5. Transverse section of cardiac muscle: hyalin degeneration in muscle fibers, Zenker necrosis, intense mononuclear cell infiltration (region shown with arrows), H\&E Bar: $50 \mu \mathrm{m}$

and had pyknotic nuclei, and an intense lymphocytic cell infiltration occured in these regions. In longitudinal sections, muscle fibers were non-striated, swollen and homogenously pink and had pyknotic nuclei, and an intense mononuclear cell infiltration was observed 
between muscle fibers. The cellular infiltration was too intense for a clear observation of muscle fibers in certain regions. These macroscopic and microscopic findings are similar to previously reported findings $(1,8,12)$.

Oxidative stress plays an important role in several pathological events, including the pathogenesis of FMD $(2,17,25)$. It has been reported that while the total oxidant capacity is increased in cattle with FMD, the total antioxidant capacity remains unchanged (2). Another study (25) reported that serum and saliva MDA levels were significantly higher in bulls with FMD compared to control animals, and that GSH levels decreased dramatically as antioxidant capacity weakened. Yet another study reported that MDA levels were significantly increased in animals with FMD, and that antioxidant treatment should be administered in viral diseases, such as FMD (17). In addition, increased MDA parameters and decreased SOD and total antioxidant capacity have also been reported in FMD (27). Similar to these published reports, in this study, MDA levels and the $8-\mathrm{OHdG} / 10^{6} \mathrm{dG}$ ratio in calves with FMD were significantly higher than those in the control group. However, although oxidized CoQ10 levels were higher in calves with FMD, the difference was not significant compared to the control group. None of the studies on FMD in calves has examined CoQ10 and $8-\mathrm{OHdG}$ levels, which makes our study unique in its contribution to the biochemical study of FMD.

The findings of the present study indicate that oxidative stress was significantly increased in calves with FMD. This means that lipid peroxidation and oxidative DNA damage may play an important role in the etiopathogenesis of FMD. This is the first study to report CoQ10 and 8-OHdG levels in calves with FMD, and its findings will form the basis for further studies on the role of oxidative stress in FMD.

\section{References}

1. Alexandersen S., Zhang Z., Donaldson A. I., Garland A. J. M.: The pathogenesis and diagnosis of foot-and-mouth disease. J. Comp. Path. 2003, 129, 1-36.

2. Bozukluhan K., Atakisi O.: Nitric oxide levels, total antioxidant and oxidant capacity in cattle with food and mouth disease. Kafkas Univ. Vet. Fak. Derg. 2013, 19, 179-181.

3. Bozukluhan K., Merhan O., Cihan M., Gokce G.: Determination of the levels of some oxidative stress parameters in calves with omphalitis. F. U. Sag. Bil. Vet. Derg. 2016, 30, 79-81

4.Bulut G., Basbugan Y., Ari E., Erten R., Bektas H., Alp H. H., Bayram I. Paricalcitol may improve oxidative DNA damage on experimental amikacininduced nephrotoxicity model. Renal Failure 2016, 38, 751-758.

5. Geyik S., Altunisik E., Neyal A. M., Taysi S.: Oxidative stress and DNA damage in patients with migraine. J. Headache Pain. 2016, 17, 1-6.

6. Gokce G., Gokce H. I., Gunes V., Erdogan H. M., Citil M.: Alterations in some haematological and biochemical parameters in cattle suffering from foot-andmouth disease. Turk. J. Vet. Anim. Sci. 2004, 28, 723-727.

7. Grotto D., Maria L. S., Valentini J., Paniz C., Schmitt G., Garsia S. C., Pomblum V. J., Rocha J. B. T., Farina M.: Importance of the lipid peroxidation biomarkers and methodological aspects for malondialdehyde quantification. Quim. Nova 2009, 32, 169-174.

8. Gulbahar M. Y., Davis W. C., Guvenc T., Yarim M., Parlak U., Kabak Y. B.: Myocarditis associated with foot-and-mouth desease virus type 0 in lambs. Vet. Pathol. 2007, 44, 589-599.
9. Huyut Z., Sekeroglu M. R., Balahoroglu R., Alp H. H., Cokluk E.: In stored human blood, the inhibitor effect of tannic acid and caffeic acid on lipid peroxidation and oxidative DNA damage. Eastern J. Med. 2016, 21, 88-93.

10. Jezek J., Klopcic M., Klinkon M.: Influence of age on biochemical parameters in calves. Vet. Inst. Pulawy 2006, 50, 211-214.

11. Kaur H., Halliwell B.: Measurement of oxidized and methylated DNA bases by HPLC with electrochemical detection. Biochem. J. 1996, 318, 21-23.

12. Kaya A., Kozat S., Ozkan C., Yildirim S., Akgul Y., Akgul O.: Serum homocysteine levels in calves with foot-and-mouth disease. JAVA 2013, 12, 1357-1361.

13. Khoschsorur G. A., Winklhofer-Roob B. M., Rabl H., Auer T. H., Peng Z., Schaur R. J.: Evaluation of a sensitive HPLC method for the determination of malondialdehyde, and application of the method to different biological materials. Chromatographia 2000, 52, 181-184.

14. Kitching R. P.: Clinical variation in foot-and-mouth disease: cattle. Rev. Sci. Tech. off. Int. Epiz. 2002, 21, 499-504.

15. Littarru G. P., Mosca F., Fattorini D., Bompadre S., Battino M.: Assay of coenzyme q10 in plasma by a single dilution step. Methods in Enzymology 2004, 378, 170-176.

16. Macunluoglu B., Atakan A., Ari E., Kaya Y., Kaspar C., Demir H., Alp H. H.: Epicardial fat tissue thickness is correlated with diminished levels of coenzyme q10, a major antioxidant molecule among hemodialysis patients. Clin. Biochem. 2014, 47, 1231-1234.

17. Mousa S. A., Galal M. K. H.: Alteration in clinical, hemobiochemical and oxidative stress parameters in Egyptian cattle infected with foot-and-mouth disease. J. Anim. Sci. Adv. 2013, 3, 485-491.

18. Ostman B., Sjodin A., Michaelsson K., Byberg L.: Coenzyme q10 supplementation and exercise-induced oxidative stress in humans. Nutrition 2012, 28, 403-417.

19. Ozcan O., Erdal H., Cakirca G., Yonden Z.: Oxidative stress and its impacts on intracellular lipids, proteins and DNA. J. Clin. Exp. Invest. 2015, 6, 331-336.

20. Radak Z., Kumagai S., Nakamoto H., Goto S.: 8-oxoguanosine and uracil repair of nuclear and mitochondrial DNA in red and white skeletal muscle of exercise-trained old rats. J. Appl. Physiol. 2007, 102, 1696-1701.

21. Tabakoglu E., Durgut R.: Oxidative stress in veterinary medicine and effects in some important diseases. AVKAE Derg. 2013, 3, 69-75.

22. Tarng D. C., Huang T. P., Wei Y. H., Liu T. Y., Chen H. W., Chen T. W., Yang W. C.: 8-hydroxy-2-'deoxyguanosine of leukocyte DNA as a marker of oxidative stress in chronic hemodialysis patients. Am. J. Kidney Dis. 2000, 36, 934-944

23. Tunca R., Sozmen M., Erdogan H., Citil M., Uzlu E., Ozen H., Gokce E. Determination of cardiac troponin I in the blood and heart of calves with foot-and-mouth disease. J. Vet. Diagn. Invest. 2008, 20, 598-605.

24. Uslu C., Taysi S., Bakan N.: Lipid peroxidation and antioxidant enzyme activities in experimental maxillary sinusitis. Ann. Clin. Lab. Sci. 2003, 33, $18-22$

25. Uzlu E., Karapehlivan M., Erdogan H. M., Kiziltepe S., Erkilic E. E., Deveci H. A., Gokce E., Kaya I., Citil M.: Serum and saliva sialic acid and oxidative stress parameters changes in bulls with foot-and-mouth disease. Kafkas Univ. Vet. Fak. Derg. 2016, 22, 321-325

26. Valavanidis A., Vlachogianni T., Fiotakis C.: 8-hydroxy-2'-deoxyguanosine (8-ohdg): a critical biomarker of oxidative stress and carcinogenesis. J. Environmental Sci. Health, Part C 2009, 27, 120-139.

27. Zaher K. S., Ahmed W. M.: Impact of foot-and-mouth disease on oxidative status and ovarian activity in Egyptian buffaloes. WJZ 2008, 3, 1-7.

Corresponding author: Assoc. Prof. Dr. Cumali Özkan, Van Yuzuncu Yil University, Faculty of Veterinary Medicine, Department of Internal Medicine, Van-Turkey; e-mail: cumaliozkan@gmail.com 